\title{
FT-IR and FT-Raman Spectral Investigation and DFT Computations of Pharmaceutical Important Molecule: Ethyl 2-(4-Benzoyl-2,5- Dimethylphenoxy) Acetate Amalanathan $\mathbf{M}^{1^{*}}$, Suresh $\mathrm{DM}^{2}$, Hubert Joe $\mathbf{I}^{3}$, Bena Jothy $\mathrm{V}^{4}$, Sebastian $\mathbf{S}^{5}$ and Ayyapan $\mathbf{S}^{6}$
}

${ }^{1}$ Annai Velankanni College, Department of Physics, Tholayavattam, Tamil Nadu India ${ }^{2}$ Department of Physics, Government Arts College, Ushagamandalam, Tamil Nadu, India

${ }^{3}$ Centre for Molecular and Biophysics Research, Department of Physics, Mar Ivanios College, Thiruvananthapuram, Kerala, India ${ }^{4}$ Department of Physics, Women's Christian College, Nagercoil, Tamil Nadu, India

${ }^{5}$ P.G and Research Department of Physics, St.Joseph's College of Arts and Science (Autonomous), Cuddalore, India

${ }^{6}$ Government College of Technology, Coimbatore 641 013, India

\begin{abstract}
The vibrational contribution studies of Pharmaceutical activity of Ethyl 2-(4-benzoyl-2,5-dimethylphenoxy)acetate (EBDA) have been performed using FTIR, FT-Raman analysis. More support on the experimental findings were added from the quantum chemical studies performed with DFT (B3LYP) method using 6-311++G (d, p) basis sets. The observed FT-IR and FT-Raman spectra have been compared with the calculated theoretical data. The calculated vibrational data have also been found in good agreement with the experimental results. Natural bond orbital analysis revealed important details of the electronic structure and dominant intramolecular interactions in Ethyl 2-(4-benzoyl-2,5-dimethylphenoxy)acetate. The HOMO and LUMO analysis reveals the possibility of charge transfer within the molecule and the possibility of Pharmaceutical activity of EBDA molecule. In addition, molecular electrostatic potential (MEP), charge analysis also were investigated using theoretical calculations.
\end{abstract}

Keywords: Vibrational spectra; DFT; NBO; PED; HOMO-LUMO; Pharmaceutical important

\section{Introduction}

Phenoxyacetic acid, a well-known aryloxyacetic acid, which is useful in the treatment of insulin resistance, and hyperglycaemia, has been investigated by various researchers [1-3]. Phenoxyacetic acid and substituted phenoxyacetic acids have potential biological properties and so these acids are widely used in herbicides [4] and pesticides [5] formulations. Antimicro-bioactivity [6], anticancer, antitumor, analgesic, anti-inflammatory, plant growth regulation and inhibition of tillage are also some of its reported properties. Hydroxy benzophenones can be attained from natural products $[7,8]$ and also by synthetic methods [9-11]. The enormous importance of these substances is essentially due to the diverse biological and chemical properties they acquire. Benzophenone analogues with nitro substituent exhibit significant in vivo antitumor activity and they have been reported to show activity such as immune modulators [12]. The title compound Ethyl 2-(4-benzoyl-2, 5-dimethylphenoxy) acetate (EBDA), has been synthesized via Fries rearrangement of hydroxy benzophenone [13].

In recent years, there has been an increasing interest in the application of DFT calculations to pharmaceutical drugs as calculations provide additional interpretation of the vibrational spectroscopic data collected [14-17]. During the past decade, DFT [18] has been accepted by the $\mathrm{ab}$ initio quantum chemistry community as a popular approach for the computation of molecular structure, vibrational frequencies and energies of chemical reactions. Calculation of vibrational frequencies using DFT provides a promising cost effective approach for calculating vibrational spectra of large molecules. In recent theoretical studies, the harmonic vibrational frequencies for a larger number of small and well studied organic molecules have been computed with HF, MP2 and DFT methods [19-21].

Vibrational spectroscopy is highly sensitive to the structural changes and is useful for the study of the pharmacological properties $[22,23]$. Accordingly, in order to understand the relationship between molecular structure and biological activity, the knowledge of the electronic structure and complete vibrational spectra are particularly important. Information about the geometry and structure of the molecule and its electrostatic potential surfaces, together with a complete analysis of the vibrational spectra using Raman and infrared techniques, based on frequency, intensity and potential energy distribution over the internal coordinates helps in understanding the structural and spectral characteristics, by allowing us to obtain a quantitative as well as qualitative understanding of energy distribution. $A b$ initio $\mathrm{HF}$ and DFT calculations have been independently performed as they form the basis of the assignment of the vibrational spectrum.

The present work deals with the optimization of molecular structure and analysing the vibrational spectra using FT-Raman and FT-IR techniques for the title compound and comparing them with the theoretical Raman and IR spectra computed by DFT method. Calculated Potential energy distribution enables to make a detailed assignment of the vibrational spectra. Natural bond orbital analysis has been performed to identify the possible intra- and inter- molecular interactions present in the compound. HOMO-LUMO energy gap calculated confirms the occurrence of charge transfer interaction. Electrostatic potential analysis has also been made to identify the mapping surface of the molecule.

\section{Materials and Method}

\section{Computational}

Molecular structure, vibrational frequencies and energies of optimized geometries have been computed employing DFT [24] with

*Corresponding author: Amalanathan M, Annai Velankanni College, Department of Physics, Tholayavattam, Tamil Nadu, India, Tel: +91-9940347178; E-mail: nathan.amalphysics@gmail.com

Received November 27, 2015; Accepted January 05, 2016; Published January 08, 2016

Citation: Amalanathan M, Suresh DM, Joe IH, Jothy VB, Sebastian S, et al. (2016) FT-IR and FT-Raman Spectral Investigation and DFT Computations of Pharmaceutical Important Molecule: Ethyl 2-(4-Benzoyl-2,5-Dimethylphenoxy) Acetate. Pharm Anal Acta 7: 457. doi:10.4172/2153-2435.1000457

Copyright: (c) 2016 Amalanathan M, et al. This is an open-access article distributed under the terms of the Creative Commons Attribution License, which permits unrestricted use, distribution, and reproduction in any medium, provided the original author and source are credited. 
Citation: Amalanathan M, Suresh DM, Joe IH, Jothy VB, Sebastian S, et al. (2016) FT-IR and FT-Raman Spectral Investigation and DFT Computations of Pharmaceutical Important Molecule: Ethyl 2-(4-Benzoyl-2,5-Dimethylphenoxy) Acetate. Pharm Anal Acta 7: 457. doi:10.4172/21532435.1000457

Gaussian '09 program package [25] using Becke's three parameter hybrid exchange functional with Lee-Yang-Parr correlation functional (B3LYP) [26-28] as a cost effective approach. The basis set 6-311++G $(\mathrm{d}, \mathrm{p})$ augmented by 'd' polarization functions on heavy atoms and 'p' polarization functions on hydrogen atoms have been used $[29,30]$. Absolute Raman intensities and infrared absorption intensities have been calculated with harmonic approximation at the same level of theory as used for optimized geometries from the derivatives of polarizability and dipole moment associated with each normal mode. Owing to the complexity of the molecule, Potential Energy Distribution has been carried out to obtain complete information of the molecular motions involved in the normal modes. The experimentally observed spectral data of the compound are found to be in good agreement with the spectral data obtained by quantum chemical calculations.

The vibrational modes have been assigned on the basis of PED analysis using VEDA program [31]. Vibrational wave numbers calculated have been scaled [32] with the scale factor in order to figure out how the calculated data are in agreement with those of the experimental ones. Calculated vibrational frequencies have been scaled down by using the scaling factor [32] to offset the systematic error caused by neglecting anharmonicity and electron density. Raman activities $\left(S_{i}\right)$ calculated have been converted to relative Raman intensities $\left(I_{i}\right)$ using the following relationship derived from the basic theory of Raman scattering $[33,34]$.

$$
I_{i}=\frac{f\left(v_{o}-v_{i}\right)^{4} S_{i}}{v_{i}\left[1-\exp \left(\frac{-h c v_{i}}{k T}\right)\right]}
$$

where $v_{o}$ is the exciting frequency (in $\mathrm{cm}^{-1}$ units), $v_{i}$ is the vibrational wave number of the $\mathrm{i}^{\text {th }}$ normal mode, $h, c$ and $k$ are universal constants, and $\mathrm{S}$ is the suitably chosen common scaling factor for all the peak intensities.

\section{Experimental}

The infrared spectrum of the sample was recorded between 4000 and $400 \mathrm{~cm}^{-1}$ on a Mattson 1000 FT-IR spectrometer which was calibrated using polystyrene bands. The sample was prepared as a $\mathrm{KBr}$ disc. FT-Raman spectrum of the sample was recorded between the region 3500 and $50 \mathrm{~cm}^{-1}$ on a Bruker FRA 106/S FT-Raman instrument using $1064 \mathrm{~nm}$ excitation from an Nd: YAG laser. The detector used was a liquid nitrogen cooled $\mathrm{Ge}$ detector.

\section{Results and Discussion}

\section{Optimized geometry}

Initial geometry generated from standard geometrical parameters was optimized and equilibrium geometry has been determined by the energy minimization. The ground state optimized structure of the molecule is presented in Figure 1. The optimized structure of EBDA and experimental structure of EBDA [13] were compared. The agreement between the optimized and experimental crystal structure is quite good showing that the geometry optimization almost exactly reproduces the experimental conformation (Figure 1) (Table 1).

The relative energies of the molecule have been calculated employing $a b$ initio functions and DFT functional (B3LYP). The optimized structural parameters (bond lengths, bond angles, dihedral angle) have been compared with those obtained experimentally for the EBDA as shown in Table 1. The table reveals that, all the theoretical values agree well with the experimental values. Calculated $\mathrm{C}-\mathrm{H}$ bond length is around $1.08 \AA$, while the experimental value from the neutron

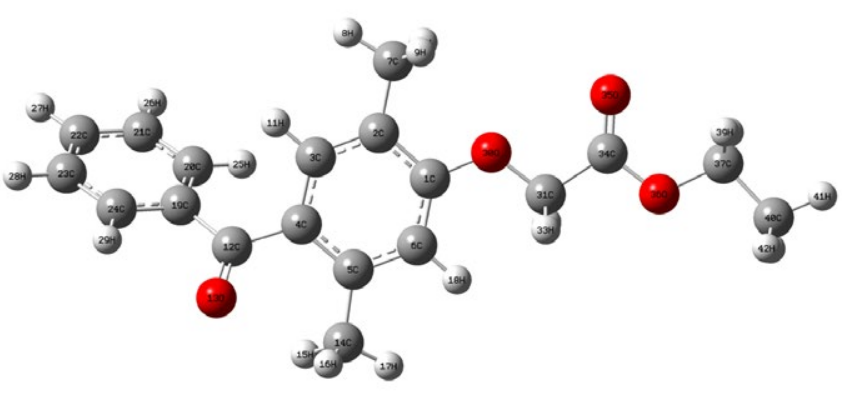

Figure 1: Optimized molecular structure of EBDA.

\begin{tabular}{|c|c|c|c|c|c|}
\hline \begin{tabular}{|l|} 
Bond \\
length \\
\end{tabular} & $\begin{array}{l}\text { Value } \\
\text { (A) }\end{array}$ & Angle & $\begin{array}{l}\text { Value } \\
\left(/^{\circ}\right)\end{array}$ & Dihedral angles & $\begin{array}{l}\text { Value } \\
\left(/^{\circ}\right)\end{array}$ \\
\hline $\mathrm{C}_{1}-\mathrm{C}_{2}$ & 1.407 & $\mathrm{C}_{1}-\mathrm{C}_{2}-\mathrm{C}_{3}$ & 117.0 & $\mathrm{C}_{1}-\mathrm{C}_{2}-\mathrm{C}_{3}-\mathrm{C}_{4}$ & 1.37 \\
\hline $\mathrm{C}_{2}-\mathrm{C}_{3}$ & 1.387 & $\mathrm{C}_{2}-\mathrm{C}_{3}-\mathrm{C}_{4}$ & 123.2 & $\mathrm{C}_{2}-\mathrm{C}_{3}-\mathrm{C}_{4}-\mathrm{C}_{5}$ & -0.42 \\
\hline $\mathrm{C}_{3}-\mathrm{C}_{4}$ & 1.407 & $\mathrm{C}_{3}-\mathrm{C}_{4}-\mathrm{C}_{5}$ & 119.1 & $\mathrm{C}_{3}-\mathrm{C}_{4}-\mathrm{C}_{5}-\mathrm{C}_{6}$ & -1.14 \\
\hline $\mathrm{C}_{4}-\mathrm{C}_{5}$ & 1.409 & $\mathrm{C}_{4}-\mathrm{C}_{5}-\mathrm{C}_{6}$ & 118.1 & $\mathrm{C}_{6}-\mathrm{C}_{1}-\mathrm{C}_{2}-\mathrm{C}_{7}$ & 179.33 \\
\hline $\mathrm{C}_{5}-\mathrm{C}_{6}$ & 1.399 & $\mathrm{C}_{1}-\mathrm{C}_{2}-\mathrm{C}_{7}$ & 120.6 & $\mathrm{C}_{3}-\mathrm{C}_{2}-\mathrm{C}_{7}-\mathrm{H}_{8}$ & -0.66 \\
\hline $\mathrm{C}_{2}-\mathrm{C}_{7}$ & 1.506 & $\mathrm{C}_{2}-\mathrm{C}_{7}-\mathrm{H}_{8}$ & 110.6 & $\mathrm{C}_{3}-\mathrm{C}_{2}-\mathrm{C}_{7}-\mathrm{H}_{9}$ & 120.02 \\
\hline $\mathrm{C}_{7}-\mathrm{H}_{8}$ & 1.091 & $\mathrm{C}_{2}-\mathrm{C}_{7}-\mathrm{H}_{9}$ & 111.2 & $\mathrm{C}_{3}-\mathrm{C}_{2}-\mathrm{C}_{7}-\mathrm{H}_{10}$ & -121.56 \\
\hline $\mathrm{C}_{7}-\mathrm{H}_{9}$ & 1.094 & $\mathrm{C}_{2}-\mathrm{C}_{7} \mathrm{H}_{10}$ & 111.3 & $\mathrm{C}_{1}-\mathrm{C}_{2}-\mathrm{C}_{3}-\mathrm{H}_{11}$ & 179.73 \\
\hline $\mathrm{C}_{7}-\mathrm{H}_{10}$ & 1.094 & $\mathrm{C}_{2}-\mathrm{C}_{3}-\mathrm{H}_{11}$ & 118.0 & $\mathrm{C}_{2}-\mathrm{C}_{3}-\mathrm{C}_{4}-\mathrm{C}_{12}$ & 175.6 \\
\hline $\mathrm{C}_{3}-\mathrm{H}_{11}$ & 1.084 & $\mathrm{C}_{3}-\mathrm{C}_{4}-\mathrm{C}_{12}$ & 119.5 & $\mathrm{C}_{3}-\mathrm{C}_{4}-\mathrm{C}_{12}-\mathrm{O}_{13}$ & -142.36 \\
\hline $\mathrm{C}_{4}-\mathrm{C}_{12}$ & 1.494 & $\mathrm{C}_{4}-\mathrm{C}_{12}-\mathrm{O}_{13}$ & 121.2 & $\mathrm{C}_{3}-\mathrm{C}_{4}-\mathrm{C}_{5}-\mathrm{C}_{14}$ & 179.41 \\
\hline $\mathrm{C}_{12}-\mathrm{O}_{13}$ & 1.223 & $\mathrm{C}_{4}-\mathrm{C}_{5}-\mathrm{C}_{14}$ & 123.4 & $\mathrm{C}_{4}-\mathrm{C}_{5}-\mathrm{C}_{14}-\mathrm{H}_{15}$ & 42.79 \\
\hline $\mathrm{C}_{5}-\mathrm{C}_{14}$ & 1.511 & $\mathrm{C}_{5}-\mathrm{C}_{14}-\mathrm{H}_{15}$ & 112.1 & $\mathrm{C}_{2}-\mathrm{C}_{5}-\mathrm{C}_{14}-\mathrm{H}_{16}$ & -75.76 \\
\hline $\mathrm{C}_{14}-\mathrm{H}_{15}$ & 1.091 & $\mathrm{C}_{5}-\mathrm{C}_{14}-\mathrm{H}_{16}$ & 110.9 & $\mathrm{C}_{4}-\mathrm{C}_{5}-\mathrm{C}_{14}-\mathrm{H}_{17}$ & 163.87 \\
\hline $\mathrm{C}_{14}-\mathrm{H}_{16}$ & 1.092 & $\mathrm{C}_{5}-\mathrm{C}_{14}-\mathrm{H}_{17}$ & 110.3 & $\mathrm{C}_{4}-\mathrm{C}_{5}-\mathrm{C}_{6}-\mathrm{H}_{18}$ & -178.64 \\
\hline $\mathrm{C}_{14}-\mathrm{H}_{17}$ & 1.092 & $\mathrm{C}_{5}-\mathrm{C}_{6}-\mathrm{H}_{18}$ & 118.1 & $\mathrm{C}_{3}-\mathrm{C}_{4}-\mathrm{C}_{12}-\mathrm{C}_{19}$ & 37.37 \\
\hline $\mathrm{C}_{6}-\mathrm{H}_{18}$ & 1.082 & $\mathrm{C}_{4}-\mathrm{C}_{12}-\mathrm{C}_{19}$ & 119.6 & $\mathrm{C}_{4}-\mathrm{C}_{12}-\mathrm{C}_{19}-\mathrm{C}_{20}$ & 32.08 \\
\hline $\mathrm{C}_{12}-\mathrm{C}_{19}$ & 1.505 & $\mathrm{C}_{12}-\mathrm{C}_{19}-\mathrm{C}_{20}$ & 122.6 & $\mathrm{C}_{12}-\mathrm{C}_{19}-\mathrm{C}_{20}-\mathrm{C}_{21}$ & 176.14 \\
\hline $\mathrm{C}_{19}-\mathrm{C}_{20}$ & 1.401 & $\mathrm{C}_{19}-\mathrm{C}_{20}-\mathrm{C}_{21}$ & 120.4 & $\mathrm{C}_{19}-\mathrm{C}_{20}-\mathrm{C}_{21}-\mathrm{C}_{22}$ & 0.9 \\
\hline $\mathrm{C}_{20}-\mathrm{C}_{21}$ & 1.394 & $\mathrm{C}_{20}-\mathrm{C}_{21}-\mathrm{C}_{22}$ & 120.1 & $\mathrm{C}_{20}-\mathrm{C}_{21}-\mathrm{C}_{22}-\mathrm{C}_{23}$ & -0.89 \\
\hline $\mathrm{C}_{21}-\mathrm{C}_{22}$ & 1.394 & $\mathrm{C}_{21}-\mathrm{C}_{22}-\mathrm{C}_{23}$ & 119.9 & C4-C12-C19-C24 & -151.92 \\
\hline $\mathrm{C}_{22}-\mathrm{C}_{23}$ & 1.396 & $\mathrm{C}_{12}-\mathrm{C}_{19}-\mathrm{C}_{24}$ & 118.2 & $\mathrm{C}_{12}-\mathrm{C}_{19}-\mathrm{C}_{20}-\mathrm{H}_{25}$ & -2.63 \\
\hline $\mathrm{C}_{19}-\mathrm{C}_{24}$ & 1.402 & $\mathrm{C}_{19}-\mathrm{C}_{20}-\mathrm{H}_{25}$ & 119.9 & $\mathrm{C}_{19}-\mathrm{C}_{20}-\mathrm{C}_{21}-\mathrm{H}_{26}$ & -179.03 \\
\hline $\mathrm{C}_{20}-\mathrm{H}_{25}$ & 1.083 & $\mathrm{C}_{20}-\mathrm{C}_{21}-\mathrm{H}_{26}$ & 119.8 & $\mathrm{C}_{20}-\mathrm{C}_{21}-\mathrm{C}_{22}-\mathrm{H}_{27}$ & 179.4 \\
\hline $\mathrm{C}_{21}-\mathrm{H}_{26}$ & 1.084 & $\mathrm{C}_{21}-\mathrm{C}_{22}-\mathrm{H}_{27}$ & 120.0 & $\mathrm{C}_{21}-\mathrm{C}_{22}-\mathrm{C}_{23}-\mathrm{H}_{28}$ & -179.81 \\
\hline $\mathrm{C}_{22}-\mathrm{H}_{27}$ & 1.084 & $\mathrm{C}_{22}-\mathrm{C}_{23}-\mathrm{H}_{28}$ & 120.0 & $\mathrm{C}_{22}-\mathrm{C}_{23}-\mathrm{C}_{24}-\mathrm{H}_{29}$ & -178.49 \\
\hline $\mathrm{C}_{23}-\mathrm{H}_{28}$ & 1.084 & $\mathrm{C}_{23}-\mathrm{C}_{24}-\mathrm{H}_{29}$ & 120.9 & $\mathrm{C}_{3}-\mathrm{C}_{2}-\mathrm{C}_{1}-\mathrm{O}_{30}$ & 179.15 \\
\hline $\mathrm{C}_{24}-\mathrm{H}_{29}$ & 1.083 & $\mathrm{C}_{2}-\mathrm{C}_{1}-\mathrm{O}_{30}$ & 115.1 & $\mathrm{C}_{2}-\mathrm{C}_{1}-\mathrm{C}_{30}-\mathrm{C}_{31}$ & 179.02 \\
\hline $\mathrm{C}_{1}-\mathrm{O}_{30}$ & 1.366 & $\mathrm{C}_{1}-\mathrm{C}_{30}-\mathrm{C}_{31}$ & 119.1 & $\mathrm{C}_{1}-\mathrm{C}_{30}-\mathrm{C}_{31}-\mathrm{H}_{32}$ & 60.08 \\
\hline $\mathrm{C}_{30}-\mathrm{C}_{31}$ & 1.408 & $\mathrm{C}_{30}-\mathrm{C}_{31}-\mathrm{H}_{32}$ & 111.7 & $\mathrm{C}_{1}-\mathrm{C}_{30}-\mathrm{C}_{31}-\mathrm{H} 33$ & -60.77 \\
\hline $\mathrm{C}_{31}-\mathrm{H}_{32}$ & 1.097 & $\mathrm{C}_{30}-\mathrm{C}_{31}-\mathrm{H}_{33}$ & 111.7 & $\mathrm{C}_{1}-\mathrm{C}_{30}-\mathrm{C}_{31}-\mathrm{C}_{34}$ & 179.4 \\
\hline $\mathrm{C}_{31}-\mathrm{H}_{33}$ & 1.096 & $\mathrm{C}_{30}-\mathrm{C}_{31}-\mathrm{C}_{34}$ & 108.7 & $\mathrm{C}_{30}-\mathrm{C}_{31}-\mathrm{C}_{34}-\mathrm{O}_{35}$ & -3.75 \\
\hline $\mathrm{C}_{31}-\mathrm{C}_{34}$ & 1.522 & $\mathrm{C}_{31}-\mathrm{C}_{34}-\mathrm{O}_{35}$ & 126.4 & $\mathrm{C}_{30}-\mathrm{C}_{31}-\mathrm{C}_{34}-\mathrm{O}_{36}$ & 176.59 \\
\hline $\mathrm{C}_{34}-\mathrm{O}_{35}$ & 1.2 & $\mathrm{C}_{31}-\mathrm{C}_{34}-\mathrm{O}_{36}$ & 108.6 & $\mathrm{C}_{31}-\mathrm{C}_{34}-\mathrm{C}_{36}-\mathrm{C}_{37}$ & 179.3 \\
\hline $\mathrm{C}_{34}-\mathrm{O}_{36}$ & 1.347 & $\mathrm{C}_{34}-\mathrm{C}_{36}-\mathrm{C}_{37}$ & 116.6 & $\mathrm{C}_{34}-\mathrm{C}_{36}-\mathrm{C}_{37}-\mathrm{H}_{38}$ & -60.27 \\
\hline $\mathrm{C}_{36}-\mathrm{C}_{37}$ & 1.453 & $\mathrm{C}_{36}-\mathrm{C}_{37}-\mathrm{H}_{38}$ & 108.4 & $\mathrm{C}_{34}-\mathrm{C}_{36}-\mathrm{C}_{37}-\mathrm{H}_{39}$ & 56.65 \\
\hline $\mathrm{C}_{37}-\mathrm{H}_{38}$ & 1.092 & $\mathrm{C}_{36}-\mathrm{C}_{37}-\mathrm{H}_{39}$ & 108.4 & $\mathrm{C}_{34}-\mathrm{C}_{36}-\mathrm{C}_{37}-\mathrm{C}_{40}$ & 178.22 \\
\hline $\mathrm{C}_{37}-\mathrm{H}_{39}$ & 1.092 & $\mathrm{C}_{36}-\mathrm{C}_{37-} \mathrm{C}_{40}$ & 107.6 & $\mathrm{C}_{36}-\mathrm{C}_{37}-\mathrm{C}_{40}-\mathrm{H}_{41}$ & 179.88 \\
\hline $\mathrm{C}_{37}-\mathrm{C}_{40}$ & 1.514 & $\mathrm{C}_{37}-\mathrm{C}_{40}-\mathrm{H}_{41}$ & 109.5 & $\mathrm{C}_{36}-\mathrm{C}_{37}-\mathrm{C}_{40}-\mathrm{H}_{42}$ & -60.6 \\
\hline $\mathrm{C}_{40}-\mathrm{H}_{41}$ & 1.093 & $\mathrm{C}_{37}-\mathrm{C}_{40}-\mathrm{H}_{42}$ & 111.1 & $\mathrm{C}_{36}-\mathrm{C}_{37}-\mathrm{C}_{40}-\mathrm{H}_{43}$ & 60.32 \\
\hline $\mathrm{C}_{40}-\mathrm{H}_{42}$ & 1.092 & $\mathrm{C}_{37}-\mathrm{C}_{40}-\mathrm{H}_{43}$ & 111.1 & & \\
\hline $\mathrm{C}_{40}-\mathrm{H}_{43}$ & 1.092 & & & & \\
\hline
\end{tabular}

Table 1: Optimized parameters of EBDA on B3LYP/6-31++G(d,p) level. 
Citation: Amalanathan M, Suresh DM, Joe IH, Jothy VB, Sebastian S, et al. (2016) FT-IR and FT-Raman Spectral Investigation and DFT Computations of Pharmaceutical Important Molecule: Ethyl 2-(4-Benzoyl-2,5-Dimethylphenoxy) Acetate. Pharm Anal Acta 7: 457. doi:10.4172/21532435.1000457

Page 3 of 8

diffraction method is 0.93 A.The difference in $\mathrm{C}-\mathrm{H}$ bond is due to experimental values taken from $\mathrm{X}$-ray diffraction method that is solid phase, but the theoretical method is the gas phase. From the above figure it is seen that the EBDA molecule consists of mono substituted phenyl ring (Ph1), Tetra substituted phenyl ring (Ph2), three methyl groups and two methylene groups. Table shows that the bond length of $\mathrm{C}_{12}-\mathrm{O}_{13}$ and $\mathrm{C}_{34}-\mathrm{O}_{35}$ varies from $1.20 \AA-1.22 \AA$ whereas the bond length of $\mathrm{C}_{1}-\mathrm{O}_{30}$ and $\mathrm{C}_{34}-\mathrm{O}_{36}$ varies from $1.34 \AA-1.36 \AA$, which substantiate the single bond and double bond nature of carbonyl group. The $\mathrm{C}-\mathrm{C}$ bond length of $\mathrm{C}_{5}-\mathrm{C}_{14}$ and $\mathrm{C}_{20}-\mathrm{C}_{7}$ is around $1.50 \AA$ while the normal C-C bond length is $1.40 \AA$. The increase in bond length from the normal value is due to electron transfer from a ring ( $\mathrm{Ph} 2)$ to the methyl group. EBDBA molecular structure is shown as a non planer surface due to the twisting between $\mathrm{Ph} 1$ to $\mathrm{Ph} 2$ and this twisting takes place due to the steric repulsion between the ring hydrogen $\mathrm{H}_{25}$ and $\mathrm{H}_{11}$. From the table, it is seen that all the experimental bond angles are in good agreement with the theoretical values.

The decrease in endocyclic angles $\mathrm{C}_{23}-\mathrm{C}_{22}-\mathrm{C}_{21}$ and $\mathrm{C}_{20}-\mathrm{C}_{19}-\mathrm{C}_{24}$ from the normal value shows the electron with drawing nature of ring. The endocyclic angle of $\mathrm{Ph} 2, \mathrm{C}_{4}-\mathrm{C}_{5}-\mathrm{C}_{6}\left(118.13^{\circ}\right)$ is decreased and the exocyclic angle, $\mathrm{C}_{4}-\mathrm{C}_{5}-\mathrm{C}_{14}\left(123.384^{\circ}\right)$ is increased from the normal value which confirms the heavy substitution of the ring. Similarly the endocyclic angle $\mathrm{C}_{3}-\mathrm{C}_{2}-\mathrm{C}_{1}\left(116.99^{\circ}\right)$ and exocyclic angle $\mathrm{C}_{3}-\mathrm{C}_{2}-\mathrm{C}_{7}$ $\left(122.42^{\circ}\right)$ shows that the methyl substitution of the ring $\mathrm{Ph} 2$ is at the para position.

\section{NBO Analysis}

NBO analysis has been proved to be an effective tool for chemical interpretation of hyper conjugative interaction and electron density transfer (EDT) from filled lone electron pairs of the $\mathrm{n}(\mathrm{Y})$ of the "Lewis base" $\mathrm{Y}$ into the unfilled anti bond $\sigma^{*}(\mathrm{X}-\mathrm{H})$ of the "Lewis acid" $\mathrm{X}-\mathrm{H}$ in X-H.....Y hydrogen bonding systems [35]. Also, in order to obtain structure of molecule, the main natural orbital interactions have been analyzed with the NBO 5.0 program [36]. Lowering of the orbital energy due to the interaction between the doubly occupied orbital and the unoccupied ones is a very convenient guide to interpret the molecular structure. In energy terms, hyper conjugation is an important effect $[37,38]$ in which an occupied Lewis-type natural bond orbital is stabilized by overlapping with a non Lewis-type orbital. This electron delocalization can be described as a charge transfer from a Lewis valence orbital (donor), with a decrease of its occupancy, to a non-Lewis orbital (acceptor). Several other types of valuable data, such as directionality, hybridization and partial charges, were analyzed in the output of NBO analysis.

Table 2 gives the second-order perturbation energy values, Eij(2) corresponding to the interactions and the overlap integral of each orbital pair. From the analysis, it is seen that the intermolecular $\mathrm{C}-\mathrm{H}$....O Hydrogen bonding is formed due to the overlap between the $\mathrm{LPO}_{13}$ and $\sigma^{*}\left(\mathrm{C}_{14}-\mathrm{H}_{17}\right)$ which result in ICT causing stabilization of the Hydrogen bond system. The NBO analysis of EBDA clearly shows the evidence of the formation $\mathrm{H}$-bonded interaction between oxygen lone pairs and $\sigma^{*}\left(\mathrm{C}_{14}-\mathrm{H}_{17}\right)$ antibonding orbital having stabilization energy $99.84 \mathrm{KJ} / \mathrm{mol}$ (Table 2).

The larger the $\mathrm{E}(2)$ values, the more intensive is the interaction between the electron donors and the electron acceptors. Among the most energetic donor acceptor $\mathrm{NBO}$ interactions, those involving p-type lone pair of oxygen atom, $\sigma\left(\mathrm{C}_{40}-\mathrm{H}_{43}\right)$ with $\sigma^{*}\left(\mathrm{C}_{14}-\mathrm{H}_{17}\right)$ antibonding have energy contributions $4661.89 \mathrm{KJ}-\mathrm{mol}^{-1}$ which shows the intermolecular dislocations in EBDA. The intermolecular hyper conjugative interactions are formed by the orbital overlap between $\pi(\mathrm{C}-\mathrm{C})$ and $\pi^{*}(\mathrm{C}-\mathrm{C})$ bond orbital's, which results in intermolecular charge transfer (ICT) and causes stabilization of system. Table shows the most important interactions between Lewis and non- Lewis orbital with oxygen lone pairs and the second order perturbation energy values E (2) corresponding to this interaction. From the Table 2. it is seen that a very strong interaction between the p-type orbital containing the lone electron pair of $\mathrm{O}_{35}$ and neighbour $\sigma^{\star}\left(\mathrm{C}_{31}-\mathrm{C}_{34}\right)$ anti bonding orbital exists.

\section{Vibrational analysis}

The vibrational spectral analysis was performed on the basis of the characteristic vibrations of the amino group, hydroxyl group, carbonyl group and methyl group. The computed wave numbers, their IR intensities and Raman activity corresponding to different modes are listed in Table 3 along with detailed assignments. The observed and simulated FT-IR and FT-Raman spectra and selected vibrational

\begin{tabular}{|c|c|c|c|c|}
\hline Donar (i) & Acceptor (j) & $\begin{array}{l}E(2)^{a} \\
(K J / m o l)\end{array}$ & $\begin{array}{l}E(j)-E(i)^{b} \\
\text { a.u. }\end{array}$ & $\begin{array}{l}F(i j)^{c} \\
a . u\end{array}$ \\
\hline$\pi\left(C_{1}-C_{6}\right)$ & $\pi^{*}(\mathrm{C} 2-\mathrm{C} 3)$ & 23.38 & 0.22 & 0.065 \\
\hline$\pi\left(C_{1}-C_{6}\right)$ & $\pi^{*}\left(\mathrm{C}_{4}-\mathrm{C}_{5}\right)$ & 22.95 & 0.30 & 0.075 \\
\hline$\sigma\left(\mathrm{C}_{1}-\mathrm{O}_{30}\right)$ & $\sigma^{*}\left(C_{7}-H_{9}\right)$ & 1657.20 & 0.03 & 0.192 \\
\hline$\sigma\left(\mathrm{C}_{1}-\mathrm{O}_{30}\right)$ & $\sigma^{*}\left(C_{12}-C_{19}\right)$ & 1422.18 & 0.03 & 0.192 \\
\hline$\sigma\left(C_{3}-C_{4}\right)$ & $\pi^{*}\left(C_{19}-C_{20}\right)$ & 3731.85 & 0.59 & 1.451 \\
\hline$\pi\left(C_{4}-C_{5}\right)$ & $\pi^{*}\left(\mathrm{C}_{2}-\mathrm{C}_{3}\right)$ & 29.89 & 0.20 & 0.070 \\
\hline$\pi\left(C_{4}-C_{5}\right)$ & $\pi^{*}\left(\mathrm{C}_{12}-\mathrm{O}_{13)}\right)$ & 33.40 & 0.10 & 0.055 \\
\hline$\pi\left(C_{19}-C_{20}\right)$ & $\sigma^{*}\left(C_{5}-C_{14}\right)$ & 269.28 & 0.57 & 0.385 \\
\hline$\pi\left(C_{19}-C_{20}\right)$ & $\sigma^{*}\left(\mathrm{C}_{7}-\mathrm{H}_{10}\right)$ & 84.75 & 0.82 & 0.259 \\
\hline$\pi\left(C_{19}-C_{20}\right)$ & $\pi^{*}\left(\mathrm{C}_{12}-\mathrm{O}_{13}\right)$ & 213.41 & 0.46 & 0.293 \\
\hline$\left.\pi\left(C_{19}-C_{20}\right)\right)$ & $\sigma^{*}\left(\mathrm{C}_{14}-\mathrm{H}_{15}\right)$ & 231.89 & 0.65 & 0.382 \\
\hline$\left.\pi\left(C_{19}-C_{20}\right)\right)$ & $\sigma^{*}\left(\mathrm{C}_{14}-\mathrm{H}_{17}\right)$ & 1148.22 & 0.24 & 0.512 \\
\hline$\left.\pi\left(C_{19}-C_{20}\right)\right)$ & $\sigma^{*}\left(\mathrm{C}_{31}-\mathrm{H}_{32}\right)$ & 108.98 & 0.72 & 0.275 \\
\hline$\left.\pi\left(C_{19}-C_{20}\right)\right)$ & $\sigma^{*}\left(\mathrm{C}_{31}-\mathrm{H}_{33}\right)$ & 103.63 & 0.74 & 0.271 \\
\hline$\left.\pi\left(C_{19}-C_{20}\right)\right)$ & $\sigma^{*}\left(C_{31}-C_{34}\right)$ & 518.18 & 0.37 & 0.422 \\
\hline $\mathrm{LP}(2) \mathrm{O}_{35}$ & $\sigma^{*}\left(C_{31}-C_{34}\right)$ & 296.83 & 0.05 & 0.111 \\
\hline $\mathrm{LP}(2) \mathrm{O}_{35}$ & $\sigma^{*}\left(\mathrm{C}_{34}-\mathrm{O}_{36}\right)$ & 30.98 & 0.65 & 0.129 \\
\hline $\mathrm{LP}(1) \mathrm{O}_{13}$ & $\sigma^{*}\left(\mathrm{C}_{14}-\mathrm{H}_{16}\right)$ & 99.84 & 0.23 & 0.136 \\
\hline $\operatorname{LP}(2) \mathrm{O}_{36}$ & $\pi^{*}\left(\mathrm{C}_{34}-\mathrm{O}_{35}\right)$ & 43.91 & 0.36 & 0.112 \\
\hline
\end{tabular}

Table 2: Second order perturbation theory analysis of Fock matrix in NBO basis for EBDA.

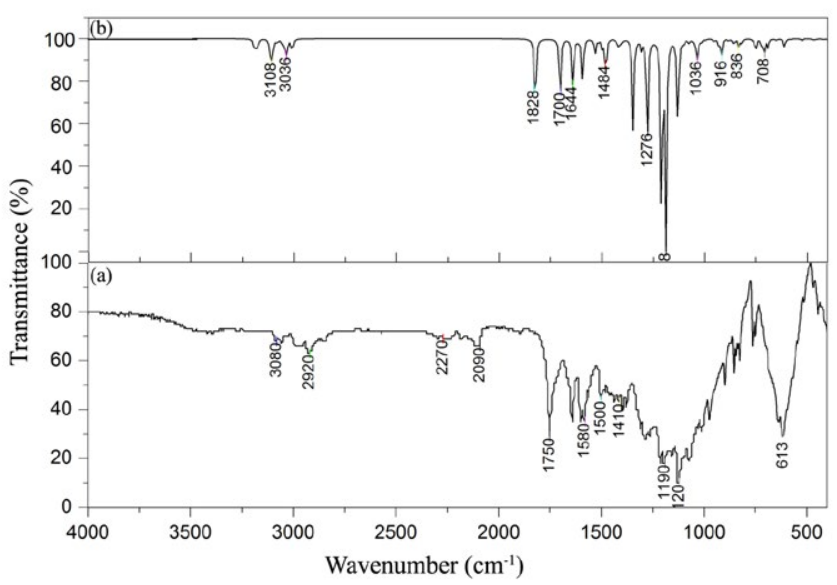

Figure 2: (a) Experimental and (b) simulated FT-IR spectra of EBDA in the range $4000-400 \mathrm{~cm}^{-1}$. 
Citation: Amalanathan M, Suresh DM, Joe IH, Jothy VB, Sebastian S, et al. (2016) FT-IR and FT-Raman Spectral Investigation and DFT Computations of Pharmaceutical Important Molecule: Ethyl 2-(4-Benzoyl-2,5-Dimethylphenoxy) Acetate. Pharm Anal Acta 7: 457. doi:10.4172/21532435.1000457

normal modes are shown in Figures 2 and 3.

Phenyl ring vibrations: The hetero aromatic structure shows the presence of C-H stretching vibration in the region of 3100-3000 $\mathrm{cm}^{-1}$ which is the characteristic region for the ready identification of $\mathrm{C}-\mathrm{H}$ stretching vibration [39]. In this region, the bands are not affected appreciably by the nature of the substituent. The $\mathrm{C}-\mathrm{H}$ stretching modes usually appear with strong Raman intensity and are highly polarized. Owing to this high polarization, Raman bands have not been observed in the experimental spectra. The observed weak band in IR at $3086 \mathrm{~cm}^{-1}$ and in Raman at 3106 and $3083 \mathrm{~cm}^{-1}$ are assigned to the $\mathrm{C}-\mathrm{H}$ stretching mode of ring 1 . The same mode observed in IR at 3060 and $3045 \mathrm{~cm}^{-1}$ and in Raman at 3072 and $3052 \mathrm{~cm}^{-1}$ is assigned for ring 2 (Figures 2 and 3) (Table 3).

PED corresponding to this vibration is a pure mode as it is evident from the contribution of $\sim 100 \%$. The $\mathrm{C}-\mathrm{H}$ stretching anharmonic wave number lies between 3100 and $3000 \mathrm{~cm}^{-1}$. The $\mathrm{C}-\mathrm{H}$ in-plane bending frequencies appear in the range of $1000-1300 \mathrm{~cm}^{-1}$ and are very useful for characterization purposes [39]. The observed series of strong bands in IR at $1310,1280,1258,1200,1157 \mathrm{~cm}^{-1}$ is assigned to the $\mathrm{C}-\mathrm{H}$ inplane bending vibration of phenyl ring 2 . The observed strong bands at $1070,1014 \mathrm{~cm}^{-1}$ in IR are assigned to the $\mathrm{C}-\mathrm{H}$ in plane bending vibration of phenyl ring 1 . The same mode of vibration of ring 2 is observed in Raman at $1152 \mathrm{~cm}^{-1}$ as a medium band. PED confirms that these vibrations are of mixed mode as is evident from the table.

The $\mathrm{C}-\mathrm{H}$ out of plane bending vibrations is strongly coupled vibrations and occurs in the region of $1000-750 \mathrm{~cm}^{-1}$ [40,41]. The aromatic $\mathrm{C}-\mathrm{H}$ out-of-plane bending vibrations of EBDA are assigned to the bands observed at 898 and $803 \mathrm{~cm}^{-1}$ in the FT-IR spectrum which is well correlated with the B3LYP method as shown in table with a PED contribution of $\sim 70-90 \%$. Also the bands in the FT-IR spectrum, at 899 , $764 \mathrm{~cm}^{-1}$ and in FT-Raman spectrum at 881 and $805 \mathrm{~cm}^{-1}$ are assigned to $\mathrm{C}-\mathrm{H}$ stretching vibrations. Benzene ring possesses six stretching vibrations, of which four occur near the highest wave number 1600 , 1580,1490 and $1440 \mathrm{~cm}^{-1}$. In the absence of ring conjugation, the band near $1580 \mathrm{~cm}^{-1}$ is usually weaker than that near $1600 \mathrm{~cm}^{-1}$. The fifth ring stretching vibration is active near $1335 \pm 35 \mathrm{~cm}^{-1}$, the region which overlaps strongly with that of the $\mathrm{C}-\mathrm{H}$ in-plane deformation and the intensity is in general, low, medium or high [41].

The sixth ring stretching vibration or ring breathing mode appears as a weak band near $1000 \mathrm{~cm}^{-1}$ in mono, 1,3-di and 1,3,5-trisubstituted benzenes. For substituted benzene, however, this vibration is substituent sensitive and is difficult to distinguish from the ring inplane deformation. In EBDA the $\mathrm{C}$-C stretching vibrations are observed in the FT-IR and FT-Raman spectra at $1550,1558,1500 \mathrm{~cm}^{-1}$ as a medium band and at $1555,1501 \mathrm{~cm}^{-1}$ as a weak band, which correlate well with the predicted theoretical data. The PED corresponding to all C-C vibrations lies between $40 \%$ and $50 \%$ as shown in Table 3 with a combination of $\mathrm{C}-\mathrm{H}$ in-plane bending in this region. The in-plane deformation vibration is at higher wave numbers than the out-ofplane vibrations [41] gave the frequency data for these vibrations for different benzene derivatives as a result of normal coordinate analysis. The theoretically computed C-C-C in-plane and out-of-plane bending vibration by the B3LYP/6-31G (d, p) method shows good agreement with the recorded spectral data.

Carbonyl group vibrations: The carbonyl group stretching vibrations give rise to the characteristic bands in IR and Raman. The intensity of these bands can increase because of the formation of hydrogen bonds. The carbonyl group vibration is observed in the region $1760-1730 \mathrm{~cm}^{-1}[42,43]$. The strong band at $1750 \mathrm{~cm}^{-1}$ is assigned to carbonyl $\mathrm{C}_{34}-\mathrm{O}_{35}$ stretching mode. The $\mathrm{C}_{12}-\mathrm{O}_{13}$ stretching mode is observed in IR at $1640 \mathrm{~cm}^{-1}$ as a medium band and the $\mathrm{C}_{12}-\mathrm{O}_{13}$ stretching vibrations are lower from the normal value. The red shifting of carbonyl stretching mode is attributed to the fact that the carbonyl group chelate with the other nucleophilic group, thereby forming both intra- and inter-molecular hydrogen bonding in the crystal. The $\mathrm{C}_{12}-\mathrm{O}_{13}$ stretching is lowered due to the formation of $\mathrm{C}-\mathrm{H}$...O hydrogen bonding in the molecule.

Methyl group vibration: Methyl group vibrations are generally referred to as electron donating substituent in the aromatic ring system, the asymmetric and symmetric $\mathrm{C}-\mathrm{H}$ stretching mode of $\mathrm{CH}_{3}$ are expected to occur around $2980 \mathrm{~cm}^{-1}$ and $2870 \mathrm{~cm}^{-1}$ [44]. The medium band observed in IR at $3005 \mathrm{~cm}^{-1}$ is assigned to the symmetric stretching of Me1. The same vibration is observed in IR and in Raman at $2986 \mathrm{~cm}^{-1}$ as a weak band and is assigned for $\mathrm{Me} 2$. The $\mathrm{Me} 3$ asymmetric stretching vibration is observed in IR at $2960 \mathrm{~cm}^{-1}$ and in Raman at $2968 \mathrm{~cm}^{-1}$ as a weak band. The shifting of the methyl (Me1 and Me2) asymmetric stretching wave number is due to the influence of the electronic effect resulting from the hyper conjugation and induction of methyl group in the aromatic ring [45]. Hyper conjugation causes the interaction of the orbital of the methyl group with the $\pi$ orbital of an aromatic ring system [46]. The Methyl Symmetric bending of Mel is observed at 1380 $\mathrm{cm}^{-1}$ in IR as a medium band. This characteristic wave number is in close agreement with those reported for the similar compounds [46]. The band observed at $854 \mathrm{~cm}^{-1}$ in IR is $\mathrm{CH}_{3}$ out of plane bending of Me1. The observed band in IR at $764 \mathrm{~cm}^{-1}$ and in Raman at $769 \mathrm{~cm}^{-1}$ is assigned to the $\mathrm{CH}_{3}$ out of plane bending modes of Me3.

Methylene group vibration: The methylene group vibrations are assigned on the basis of the spectral similarity to the related amino acid compounds. In amino acids, the $\mathrm{CH}_{2}$ asymmetric and symmetric vibrations are expected to occur in the regions 3100-3000 and 3000$2900 \mathrm{~cm}^{-1}$ respectively [47-49]. The observed weak band in Raman at $3023 \mathrm{~cm}^{-1}$ is assigned to asymmetric stretching of $\mathrm{C}_{37}-\mathrm{H}_{2}$. The $\mathrm{C}_{31}-\mathrm{H}_{2}$ symmetric stretching is observed as a weak band in Raman at 2985 $\mathrm{cm}^{-1}$. Electronic effects including back-donation, mainly caused by the presence of nitrogen atom adjacent to methylene groups, which can shift the position and alter the intensity of $\mathrm{C}-\mathrm{H}$ stretching and bending modes. The scissoring mode of the $\mathrm{CH}_{2}$ group gives rise to characteristic band near $1420-1412 \mathrm{~cm}^{-1}$. The scissoring mode of the $\mathrm{C}_{31}-\mathrm{H}_{2}$ group is observed in IR at $1440 \mathrm{~cm}^{-1}$ as a medium band. The rocking and wagging vibrations appear in the region of $1309-1288 \mathrm{~cm}^{-1}$ and $910-905 \mathrm{~cm}^{-1}$ respectively. The observed $\mathrm{CH}_{2}$ deformations are given in Table 3.

\section{HOMO-LUMO energy gap}

Spatial distribution of molecular orbital's, especially those of highest occupied molecular orbital and lowest available unoccupied molecular orbital, are excellent indicators of electron transport in molecular systems. Conjugated molecules are generally characterized by a small HOMO-LUMO separation, which is the result of a significant degree of intra molecular change transfer (ICT) from the end-capping electron donor groups to the efficient electron acceptor groups through conjugated path. In EBDA, the HOMO-LUMO energy gap is 4.4913 $\mathrm{eV}$ and the lowering of this gap is essentially a consequence of the large stabilization of the LUMO due to the strong electron-accepting ability of the electron-acceptor group. The HOMO and LUMO orbital's are shown in Figure 4. In EBDA the atomic $\pi$-orbital's point towards each other and have better overlap, an increase in $\pi$-character points the fact that sigma bonds are stronger as evidenced by $\mathrm{NBO}$ analysis. A highly delocalized LUMO indicates that the electrons can more readily move 
Citation: Amalanathan M, Suresh DM, Joe IH, Jothy VB, Sebastian S, et al. (2016) FT-IR and FT-Raman Spectral Investigation and DFT Computations of Pharmaceutical Important Molecule: Ethyl 2-(4-Benzoyl-2,5-Dimethylphenoxy) Acetate. Pharm Anal Acta 7: 457. doi:10.4172/21532435.1000457

Page 5 of 8

\begin{tabular}{|c|c|c|c|}
\hline $\begin{array}{l}\text { Cal } \\
\text { Freq. }\end{array}$ & Exp IR & Exp. Raman & TED (\%) \\
\hline 3091 & - & 3106 w & $\mathrm{U}_{\mathrm{C}-\mathrm{H}}$ ar in ring $1(88)$ \\
\hline 3087 & 3086 w & 3083 w & $\mathrm{U}_{\mathrm{C}-\mathrm{H}}$ ar in ring $1(88)$ \\
\hline 3086 & - & - & $\mathrm{U}_{\mathrm{C}-\mathrm{H}}$ ar in ring $2(45)$ \\
\hline 3078 & - & - & $\mathrm{U}_{\mathrm{C}-\mathrm{H}}$ ar in rin(88)g $1(83)$ \\
\hline 3073 & - & 3072 w & $\mathrm{U}_{\mathrm{C}-\mathrm{H}}$ ar in ring $2(96)$ \\
\hline 3068 & 3060 w & - & $\mathrm{U}_{\mathrm{C}-\mathrm{H}}$ ar in ring 1 (82) \\
\hline 3058 & 3045 w & 3052 w & $\mathrm{U}_{\mathrm{C}-\mathrm{H}}$ ar in ring $1(87)$ \\
\hline 3015 & - & 3023 w & $\mathrm{C}_{37}-\mathrm{H}_{2}$ Asym Stretching (96) \\
\hline 3006 & - & 3005 w & Me1 Asym. Stretching (90) \\
\hline 3006 & - & - & Me1 Asym. Stretching (96) \\
\hline 3002 & - & - & Me3 Asym. Stretching (95) \\
\hline 2997 & - & - & $\mathrm{C}_{31-} \mathrm{H}_{2}$ Sym. Stretching (97) \\
\hline 2989 & - & 2986 w & Me2 Asym. Stretching (95) \\
\hline 2979 & 2960 w & 2968 w & Me3 Asym. Stretching (99) \\
\hline 2955 & - & 2952 w & $\mathrm{C}_{31-} \mathrm{H}_{2}$ Sym. Stretching (98) \\
\hline 2946 & - & - & $\begin{array}{l}\mathrm{C}_{31} \mathrm{H}_{2} \text { Asym Stretching } \mathrm{C} 31 \mathrm{H} 2 \\
\text { Sym. Stretching (97) }\end{array}$ \\
\hline 2939 & - & - & $\begin{array}{l}\text { Me2 Sym. Stretching C31H2 Sym. } \\
\text { Stretching (98) }\end{array}$ \\
\hline 2938 & - & & $\begin{array}{l}\text { Me3 Sym. Stretching C31H2 Sym. } \\
\text { Stretching (99) }\end{array}$ \\
\hline 2931 & $2930 \mathrm{w}$ & $2930 \mathrm{w}$ & Me1 Sym. Stretching (84) \\
\hline 2909 & - & 2895 w & $\mathrm{C}_{31}-\mathrm{H}_{2}$ Sym Stretching (98) \\
\hline 1764 & $1750 \mathrm{~s}$ & - & $\mathrm{C}_{34}-\mathrm{O}_{35}$ Stretching (90) \\
\hline 1647 & $1640 \mathrm{~m}$ & - & $\mathrm{C}_{12}-\mathrm{O}_{13}$ Stretching (85) \\
\hline 1589 & $1600 \mathrm{~m}$ & - & $\mathrm{U}_{\mathrm{C}-\mathrm{C}}$ ar in ring $2(45)$ \\
\hline 1582 & 1580 m & - & $\mathrm{U}_{\mathrm{C}-\mathrm{C}}$ ar in ring $1(67)$ \\
\hline 1563 & $1558 \mathrm{~m}$ & 1555 w & $\mathrm{U}_{\mathrm{C}-\mathrm{C}}$ ar in ring $1(47)$ \\
\hline 1541 & - & - & $\mathrm{U}_{\mathrm{C}-\mathrm{C}}$ ar in ring $2(57)$ \\
\hline 1483 & $1500 \mathrm{~m}$ & $1501 \mathrm{w}$ & $\mathrm{U}_{\mathrm{C}-\mathrm{C}}$ ar in ring $2(49)$ \\
\hline 1469 & - & - & $\mathrm{C}_{37-} \mathrm{H}_{2}$ Sissoring (86) \\
\hline 1467 & - & - & $\mathrm{U}_{\mathrm{C}-\mathrm{C}}$ ar in ring $2(71)$ \\
\hline 1449 & - & - & Me1, Me2 Asym.Bending (67) \\
\hline 1448 & - & - & Me3 Asym.Bending (63) \\
\hline 1439 & $1440 \mathrm{~m}$ & - & $\mathrm{C}_{31-} \mathrm{H}_{2}$ Sissoring $(72)$ \\
\hline 1438 & - & - & Me3 Asym. Bending (61) \\
\hline 1435 & - & - & $\mathrm{C}_{31} \mathrm{H}_{2}$ Sissoring (66) \\
\hline 1428 & - & - & Me1, Me2 Asym. Bending (77) \\
\hline 1428 & - & - & Me1, Me2 Asym. Bending (64) \\
\hline 1426 & - & - & $\delta_{\mathrm{C}-\mathrm{H}}$ ar in ring $1(20)$ \\
\hline 1385 & - & - & $\mathrm{C}_{37-} \mathrm{H}_{2}$ Wagging (28) \\
\hline 1377 & 1380 m & - & Me1 Sym. Bending (60) \\
\hline 1373 & - & - & Me2 Sym. Bending (75) \\
\hline 1369 & - & - & $\mathrm{C}_{31-} \mathrm{H}_{2}$ Wagging (33) \\
\hline 1359 & - & - & Me1 Sym. Bending (23) \\
\hline 1348 & - & - & $\delta_{\mathrm{C}-\mathrm{H}}$ ar in ring $2(65)$ \\
\hline 1306 & $1310 \mathrm{~s}$ & - & $\delta_{\mathrm{C}-\mathrm{H}}$ ar in ring $2(75)$ \\
\hline 1303 & - & - & $\mathrm{U}_{\mathrm{C}-\mathrm{C}}$ ar in ring $1(26)$ \\
\hline 1288 & $1280 \mathrm{~s}$ & - & $\delta_{C-H}$ ar in ring $2(63)$ \\
\hline 1265 & - & - & $\mathrm{C}_{37-} \mathrm{H}_{2}$ Twisting (49) \\
\hline 1256 & $1258 \mathrm{~s}$ & - & $\delta_{C-H}$ ar in ring $2(76)$ \\
\hline 1243 & - & - & $\delta_{\mathrm{C}-\mathrm{H}}$ in ring $1(69)$ \\
\hline 1236 & - & - & $\mathrm{C}_{31-} \mathrm{H}_{2}$ Twisting (42) \\
\hline 1218 & 1200 vs & - & $\delta_{\mathrm{C}-\mathrm{H}}$ ar in ring $2(88)$ \\
\hline 1171 & - & - & $\mathrm{C}_{31} \mathrm{H}_{2}$ Rocking (38) \\
\hline 1170 & - & - & $\delta_{\mathrm{C}-\mathrm{H}}$ ar in ring $1(51)$ \\
\hline
\end{tabular}

\begin{tabular}{|c|c|c|c|}
\hline 1162 & - & - & $\delta_{\mathrm{C}-\mathrm{H}}$ ar in ring $1(46)$ \\
\hline 1149 & 1157 vs & 1152 m & $\delta_{\mathrm{C}-\mathrm{H}}$ ar in ring $2(41)$ \\
\hline 1143 & - & - & $\delta_{\mathrm{C}-\mathrm{H}}$ ar in ring $2(79)$ \\
\hline 1137 & 1120 vvs & $1132 \mathrm{~m}$ & $\mathrm{C}_{37-} \mathrm{H}_{2}$ Twisting (76) \\
\hline 1098 & - & $1100 \mathrm{~m}$ & $\mathrm{C}_{37-} \mathrm{H}_{2}$ Rocking $(70)$ \\
\hline 1092 & - & - & $\delta_{\mathrm{C}-\mathrm{H}}$ ar in ring $1(40)$ \\
\hline 1067 & $1070 \mathrm{~s}$ & - & $\delta_{C-H}$ ar in ring $1(71)$ \\
\hline 1041 & - & - & $\mathrm{C}_{5}-\mathrm{C}_{14}$ Stretch (28) \\
\hline 1028 & - & - & Me1 Bending (77) \\
\hline 1019 & - & - & Me2 Bending (61) \\
\hline 1013 & $1014 \mathrm{~s}$ & & $\delta_{\mathrm{C}-\mathrm{H}}$ ar in ring $1(42)$ \\
\hline 1011 & - & - & Me2 Bending (41) \\
\hline 1001 & - & - & Me3 Bending (65) \\
\hline 1000 & & 991 vvs & $\mathrm{C}_{37-} \mathrm{H}_{2}$ Rocking (66) \\
\hline 983 & - & - & Radial skel. in ring 1 (36) \\
\hline 982 & - & - & Me2 Bending (44) \\
\hline 975 & $977 \mathrm{~m}$ & - & $\delta_{\mathrm{C}-\mathrm{H}}$ ar in ring 1 (79) \\
\hline 962 & - & - & $\delta_{\mathrm{C}-\mathrm{H}}$ ar in ring $1(86)$ \\
\hline 923 & - & - & $\delta_{\mathrm{C}-\mathrm{H}}$ ar in ring $2(52)$ \\
\hline 922 & - & - & $\delta_{\mathrm{C}-\mathrm{H}}$ ar in ring $1 \delta_{\mathrm{C}-\mathrm{H}}$ ar in ring $1(66)$ \\
\hline 901 & - & - & $\delta_{C-H}$ ar in ring $2 \delta_{C-H}$ ar in ring $1(50)$ \\
\hline 888 & $899 \mathrm{~m}$ & $881 w$ & $\delta_{\mathrm{C}-\mathrm{H}}$ in ring $2 \delta_{\mathrm{C}-\mathrm{H}}$ ar in ring $1(36)$ \\
\hline $852 \mathrm{~m}$ & $854 \mathrm{~m}$ & - & Me1 out of plane $\delta_{C-H}$ ar in ring $1(76)$ \\
\hline $834 \mathrm{~m}$ & $834 \mathrm{~m}$ & - & Me2 out of plane $\delta_{C-H}$ ar in ring $1(94)$ \\
\hline $828 w$ & - & - & $\delta_{C-H}$ ar in ring $2(82)$ \\
\hline $807 w$ & - & $805 w$ & $\delta_{\mathrm{C}-\mathrm{H}}$ in ring $1(17)$ \\
\hline $791 w$ & - & - & $\delta_{\mathrm{C}-\mathrm{H}}$ ar in ring $2(27)$ \\
\hline 787 w & $764 w$ & 769 & Me3 out of plane Bending (88) \\
\hline $741 w$ & $751 w$ & $755 w$ & Radial skel. in ring 2 (29) \\
\hline $726 w$ & - & - & $\delta_{\mathrm{C}-\mathrm{H}}$ ar in ring $2(37)$ \\
\hline 699 w & - & - & Radial skel. in ring 2 (34) \\
\hline $695 w$ & - & - & $\delta_{\mathrm{C}-\mathrm{H}}$ ar in ring $2(38)$ \\
\hline 685 w & 686 vvw & $684 w$ & OP skel. in ring 1 (54) \\
\hline 667 w & - & $647 w$ & Radial skel. in ring 1 (42) \\
\hline 630 & $637 w$ & $632 w$ & OP skel. in ring 2 (25) \\
\hline 611 & $615 \mathrm{~s}$ & $619 w$ & 6b Radial skel. in ring 1 \\
\hline 590 & - & - & OP skel. in ring 2 (29) \\
\hline 586 & - & - & OP skel. in ring 2 (25) \\
\hline 563 & - & $575 w$ & OP skel. in ring 2 (23) \\
\hline 508 & $516 w$ & $543 w$ & OP skel.in ring $1(26)$ \\
\hline 457 & $470 \mathrm{vw}$ & $466 w$ & $\mathrm{C}_{2}-\mathrm{C}_{7}$ stretching (40) \\
\hline 450 & $445 \mathrm{vw}$ & $450 w$ & OP skel.in ring 1 (21) \\
\hline 436 & - & - & OP skel.in ring 2 (53) \\
\hline 409 & 416 vw & - & OP skel.in ring 1 (58) \\
\hline 401 & - & - & OP skel.in ring 1 (78) \\
\hline 384 & - & - & OP skel.in ring $2(30)$ \\
\hline 367 & - & 377 w & OP skel.in ring 1 (29) \\
\hline 340 & - & $347 w$ & C-C Bending (29) \\
\hline 318 & - & - & Me1 Torsion (39) \\
\hline 267 & - & - & Me2 Torsion (61) \\
\hline 255 & - & - & Me3 Torsion (59) \\
\hline 252 & - & $248 w$ & Me2 Torsion (18) \\
\hline 247 & - & - & OP skel.in ring 1 (43) \\
\hline 209 & - & - & OP skel.in ring 1 (46) \\
\hline 186 & - & $186 w$ & OP skel.in ring 1 (48) \\
\hline 171 & - & - & OP skel.in ring 2 (28) \\
\hline 150 & - & $158 w$ & C-O Bending (61) \\
\hline
\end{tabular}


Citation: Amalanathan M, Suresh DM, Joe IH, Jothy VB, Sebastian S, et al. (2016) FT-IR and FT-Raman Spectral Investigation and DFT Computations of Pharmaceutical Important Molecule: Ethyl 2-(4-Benzoyl-2,5-Dimethylphenoxy) Acetate. Pharm Anal Acta 7: 457. doi:10.4172/21532435.1000457

\begin{tabular}{|l|l|l|l|}
\hline 147 & - & - & C-O Bending (66) \\
\hline 143 & - & - & C-O out of plane Bending (72) \\
\hline 132 & $134 \mathrm{w}$ & OP skel.in ring 2 (47) \\
\hline 120 & $119 \mathrm{w}$ & OP skel.in ring 2 (59) \\
\hline 103 & & OP skel.in ring 1(71) \\
\hline 90 & $83 w$ & OP skel.in ring 2 (21) \\
\hline 64 & & C-O out of plane Bending (51) \\
\hline 59 & & C-O out of plane Bending (36) \\
\hline 53 & & & OP skel.in ring 2 (51) \\
\hline 44 & & & OP skel.in ring 2 (55) \\
\hline 32 & & & OP skel.in ring 2 (50) \\
\hline 22 & & & C-O out of plane Bending (76) \\
\hline 15 & & & OP skel.in ring 2 (73) \\
\hline
\end{tabular}

Table 3: Calculated and observed vibrational frequencies for EBDA and their tentative assignment.

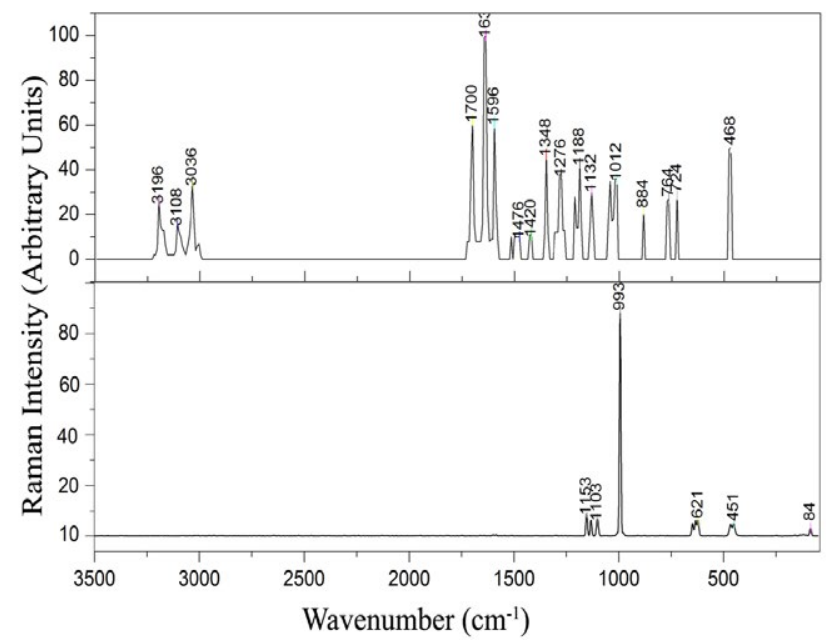

Figure 3: (a) Experimental and (b) simulated FT-Raman spectra of EBDA in the range $3500-50 \mathrm{~cm}^{-1}$.

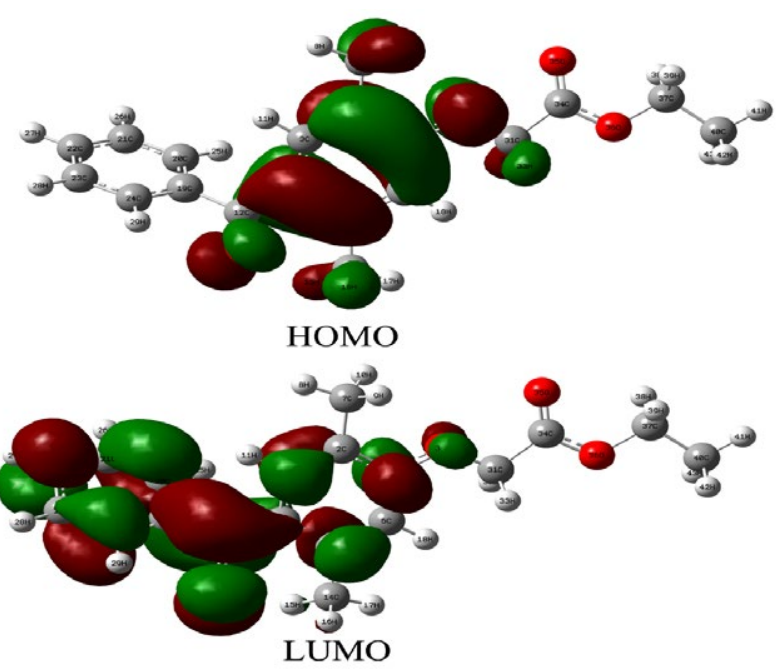

Figure 4: HOMO and LUMO plot of EBDA.

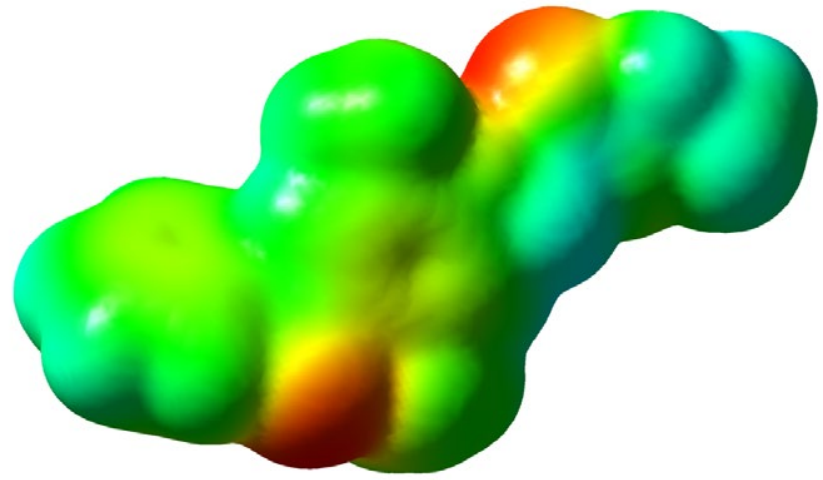

Figure 5: The MESP mapped surface of the EBDA molecule.

around the molecule from HOMO-LUMO and hence an improved ICT [50] (Figure 4).

In EBDA the LUMO strongly localizes on the phenyl ring indicating the presence of favourable atomic centres within EBDA for possible nucleophile attacks revealing its bioactivity and pharmaceutical activity. The Lowering of HOMO-LUMO energy gap confirms the possibility of ICT and HOMO-LUMO delocalization showing its possibility of nucleophile attacks which serves as an evidence for the pharmaceutical activity of the EBDA molecule. The HOMO-LUMO plot shows that both the HOMO and LUMO orbital's predominantly localize on the phenyl ring. The HOMO, LUMO and HOMO-LUMO energy gap of EBDA in the DFT level at 6-311++G $(\mathrm{d}, \mathrm{p})$ basis set has been calculated.

\section{Molecular electrostatic potential}

Molecular electrostatic potential is used primarily for predicting sites and relative reactivity's towards electrophilic attack, in studies of biological recognition and hydrogen bonding interactions [51]. To predict the reactive sites for electrophilic and nucleophilic attack for EBDA, the MEP at the B3LYP/6-311++G (d, p) method was calculated as shown in Figure 5. The different values of the electrostatic potential at the surface are represented by different colours. Electrostatic potential increases in the order red $<$ orange $<$ yellow $<$ green $<$ blue. Colour code of the maps is in the range between 0.0142 a.u. (deepest red) and 0.0142 a.u. (deepest blue) in title molecule, where blue colour indicates the strongest attractions and red indicates the strongest repulsion. The region of negative $\mathrm{V}(\mathrm{r})$ is associated with the lone pair of electrons (Figure 5).

As seen from Figure 5, in EBDA, the region having negative potential are over carbonyl group, the region having the positive potential are over the Phenyl ring and methyl group, the predominance of the light green region the MEPs surface corresponding to a potential halfway between the two extremes red and dark blue colour. The positive (blue) regions of MEP are related to electrophilic reactivity and the negative (red) regions to nucleophilic reactivity as shown in Figure 5. It can be seen from the MEP map of the present molecule that the negative regions are mainly localized on the $\mathrm{O}_{13}$ and $\mathrm{O}_{36}$ atoms. A maximum positive region is localized on the carbonyl carbon atom indicating a possible site for nucleophilic attack. MEP map shows that the negative potential sites are on electronegative atoms as well as the positive potential sites are around the carbonyl atom.

\section{Conclusion}

The detailed interpretation of the vibrational spectra has been 
Citation: Amalanathan M, Suresh DM, Joe IH, Jothy VB, Sebastian S, et al. (2016) FT-IR and FT-Raman Spectral Investigation and DFT Computations of Pharmaceutical Important Molecule: Ethyl 2-(4-Benzoyl-2,5-Dimethylphenoxy) Acetate. Pharm Anal Acta 7: 457. doi:10.4172/21532435.1000457

Page 7 of 8

carried out for the pharmaceutically important molecule Ethyl 2-(4-benzoyl-2, 5-imethylphenoxy) acetate. Molecular geometry, HOMO and LUMO energy and vibrational wave numbers of EBDA in the ground state have been calculated by using density functional theory. FT-IR and FT-Raman spectra of the EBDA have been recorded and analyzed. Observed and calculated wave numbers are found to be in good agreement. The lowering of carbonyl stretching wave number is due to the p-electron being localized. Lowering of the HOMO-LUMO energy gap value has substantial influence on the intra molecular charge transfer and pharmaceutical nature of the molecule.

\section{References}

1. Gurumurthy R, Sathyanarayana K, Gopalakrishnan M (1992) Kinetics and Mechanism of Oxidation of some para-, meta-, and ortho- substituted ethylSPhenylmercaptoacetic acid. BAB Bull Chem Soc Jpn 65: 1096-1101.

2. Karthikeyan B, Gurumurthy R, Gopalakrishnan M, Selvaraju M (1998) Kinetics and Mechanism of Oxidation of Diphenacyl sulphide by imidazolinium dichromate and Quinolinium dichromate. Asian Chem Lett 2-3: 97.

3. Timchalk C (2004) Comparative inter-species pharmacokinetics of phenoxyacetic acid herbicides and related organic acids Evidence that the dog is not a relevant species for evaluation of human health risk. Toxicology 200: 1-8.

4. Csrhati T, Forgacs E (1998) Phenoxyacetic Acids - Separation and QuantitativeDetermination. J Chromatogr B: Biomed Sci Appl 717: 157-178.

5. Crafts AS (1957) Aryloxyacetic acid and its various derivatives are used as herbicides and pesticides. Adv Pest Control Res 1: 39-79.

6. Sarac S, Safak C, Erdogan H, Abbasoglu U, Gunay Y (1991) Substituted phenoxyacetic acid derivatives and their antimicrobial activities. HÜ $\mathrm{J} F a c$ Pharm 11: 1-11

7. Kohn W, Sham LJ (1965) Self-Consistent Equations Including Exchange and Correlation Effects. Phys Rev A 140: 1133.

8. Vidya R, Eggen M, Georg GI, Himes RH (2003) Cryptophycin affinity labels: Synthesis and biological activity of a benzophenone analogue of cryptophycin-24. Bioorg Med Chem Lett 13: 757-760.

9. Hsieh HP, Liou JP, Lin YT, Mahindroo N, Chang JY, et al. (2003) Erratum to 'Structure-Activity and Crystallographic Analysis of Benzophenone Derivatives—the Potential Anticancer Agents. Bioorg Med Chem Lett 13: 101-105.

10. Schlitzer M, Bohm M, Sattler I, Bioorg (2002) Non-thiol farnesyltransferase inhibitors: structure-activity relationships of benzophenone-based bisubstrate analogue farnesyltransferase inhibitors Med Chem Lett 10: 615-635.

11. Revesz L, Blum FE, Padova EDI, Buhl TR, Feifel H, et al. (2004) SAR of benzoylpyridines and benzophenones as p38alpha MAP kinase inhibitors with oral activity. Bioorg Med Chem Lett 14: 3601-3605

12. Leonard DMJ (1997) Ras farnesyl trans ferase: a new therapeutic target. Med Chem 40: 2971-2990.

13. Devarajegowda HC, Shaukath Ara Khanum, Jeyaseelan S, Waleed AI Eryania A, Shylajakumari J (2009) Ethyl 2-(4-benzoyl-2,5-dimethylphenoxy)acetate. Acta Crys E 65: 2854-2855

14. Moroni L, Gellini C, Miranda MM, Salvi PR, Foresti ML (2008) Raman and infrared characterization of the vibrational properties of the antimalarial drug artemisinin. J Raman Spectrosc 39: 276-283.

15. Schmidt A, Lindner AS, Casado J, Ramirez FJ (2007) Vibrational spectra and quantum chemical calculations of uracilyl-pyridinium mesomeric betaine. $J$ Raman Spectrosc 38: 1500-1509.

16. Strachan CJ, Rades T, Gordon KC (2007) Analysis of sustained-release table film coats using terahertz pulsed imaging. J Pharm Pharmacol 59: 253-261.

17. Akalin E, Akyuz $S$ (2007) Vibrational structure of free and hydrogen bonded complexes of isoniazid: FT-IR, FT-Raman and DFT study. J Mol Struct 492 497.

18. Liu RF, Dennis RT, Jefferey AC, Panla RM (1996) ensity Functional Theory Study of Molecular Structures and Vibrational Spectra of 3,4- and 2,3-Pyridyne. J Phys Chem 100: 3430-3434.

19. Zhou XF, Liu RF (1997) Density functional theory study of vibrational spectra 6: assignment of fundamental vibrational frequencies of benzene isomers:
Dewar benzene, benzvalene, trimethylenecyclopropane, prismane, and 3,4-dimethylenecyclobutene Spectrochim. Acta 53: 259-269.

20. Nwobi O, Higgins J, Zhou XF, Liu RF (1997) Density-Functional Calculation O Phenoxyl Radical And Phenolate Anion - An Examination Of The Performance Of Dft Methods. Chem Phys Lett 272: 155-161.

21. Zhou ZY, Du DM, Fu AP (2000) Structures and vibrational frequencies of pyruvic acid: Density functional theory study. Vibr Spectrosc 23: 181-186.

22. Lebedev RS (2002) Low-frequency vibration spektra, strukture, and biological activity of azolidons with the $\mathrm{NH} \ldots \mathrm{X}(\mathrm{X}=\mathrm{S}, \mathrm{N}, \mathrm{O})$ intermolecular hydrogen bond. Russ Phys J 45: 822-830.

23. Kostova I, Hubert Joe I, Cinta Pinzaru S (2009) Vibrational spectral characterization of new $\mathrm{La}$ (III) and Dy(III) complexes. J Optoelectron Biomed Mater 1: 188-199.

24. Hohenberg P, Kohn W (1964) Inhomogeneous Electron Gas. Phys Rev B 136 864-871.

25. Frisch MJ, Trucks GW (2009) Gaussian-09, Revision A.02, Gaussian, Inc., Wallingford CT.

26. Lee CT, Yang WT, Parr RG (1988) Development of the Colle-Salvetti correlation-energy formula into a functional of the electron densit. Phys Rev B 37: 785-789.

27. Parr RG, Yang W (1989) Density Functional Theory of Atoms and Molecules, Oxford University Press, New York.

28. Becke AD (1993) Density-functional thermochemistry. III. The role of exact exchange. J Chem Phys 98: 5648-5652.

29. Petersson GA, Allaham MA (1991) A complete basis set model chemistry open shell system and and total energy of first row atoms. J Chem Phys 94: 60816090.

30. Petersson GA, Bennett A, Tensfeldt TG, Allaham MA, Shirley WA, et al (1988) Systematically convergent basis sets with relativistic pseudopotentials II. Small-core pseudopotentials and correlation consistent basis sets for the post-d group 16-18 elements. J Chem Phys 89: 2193-2218.

31. Jamroz MH (2004) Vibrational Energy Distribution Analysis VEDA 4, Warsaw.

32. Scott AP, Random L (1996) Harmonic Vibrational Frequencies: An Evaluation of Hartree-Fock, Moller-Plesset, Quadratic Configuration Interaction, Density Functional Theory, and Semiempirical Scale Factor. J Phys Chem 100: 1650216504.

33. Keresztury G, Holly S, Varga J, Besenyei G, Wang AY, et al. (1993) Vibrational-Spectra of Monothiocarbamates $2 \mathrm{Ir}$ And Raman-Spectra, Vibrational Assignment, Conformational-Analysis And Ab-Initio Calculations Of S-Methyl-N, N-Dimethylthiocarbamate spectrochim. Acta A 49: 2007-2026.

34. Keresztury G, Chalmers JM, Griffith PR (2002) Raman Spectroscopy: Theory in Handbook of Vibrational Spectroscopy Vol 1; John Wiley and Sons Ltd.

35. Reed AE, Curtiss LA, Weinhold F (1988) Intermolecular Interactions from a Natural Bond Orbital, Donor-Acceptor Viewpoint. Chem Rev 88: 899-926.

36. Glendening ED, Badenhoop JK, Reed AE, Carpenter JE, Bohmann JA, et al. (2001) NBO 5.0, Theoretical Chemistry Institute, University of Wisconsin, Madison.

37. Weinhold F (2001) Chemistry: a new twist on molecular shape Nature 411 : 539-541.

38. Weinhold F, Landis C (2005) Valency and Bonding: A Natural Bond Orbital Donor- Acceptor Perspective, Cambridge University Press, Cambridge.

39. Varsanyi G (1973) Assignments for Vibrational Spectra of Seven Hundred Benzene Derivatives, vol. 1-2, Academic Kiaclo, Budapest.

40. Sundaraganesan N, Ilakiamani S, Joshua BD (2007) FT-Raman and FT-IR spectra, ab initio and density functional studies of 2-amino-4,5-difluorobenzoic acid Spectrochim. Acta 67: 287-297.

41. Shimanouchi T, Kakiuti Y, Gamo I (1956) the study of chemical kinetics and chemical analysis J Chem Phys 25: 1245-1252.

42. Smith BC (1999) Infrared Spectral Interpretation, A Systematic Approach, CRC Press, Washington, DC.

43. Colthup NB, Daly LH, SE Wiberley (1990) Introduction to Infrared and Raman Spectroscopy, Academic Press, New York. 
Citation: Amalanathan M, Suresh DM, Joe IH, Jothy VB, Sebastian S, et al. (2016) FT-IR and FT-Raman Spectral Investigation and DFT Computations of Pharmaceutical Important Molecule: Ethyl 2-(4-Benzoyl-2,5-Dimethylphenoxy) Acetate. Pharm Anal Acta 7: 457. doi:10.4172/21532435.1000457

44. Gussoni M, Castiglioni C, Ramos MN, Rui MC, Zerbi G (1990) nfrared intensities: from intensity parameters to an overall understanding of the spectrum. J Mol Struct 224: 445-449.

45. Hung Y, Gilson DFR, Butler IS (1993) Vibrational spectra of two crystalline organometallic complexes of the type molecule. J Chem Phys 97: 1998-2005.

46. Kalsi PS (2005) Spectroscopy of organic compounds, sixth ed., New Age International(P) Limited Publishers, New Delhi.

47. Amalanathan M, Hubert Joe I, Prabhu SS (2010) Charge Transfer Interaction and Terahertz Studies of a Nonlinear Optical Material I-Glutamine Picrate: A DFT Study J of Phy Chem A 114: 13055-13064.
48. George S (2001) Infrared and Raman Characteristic Group Wavenumbers Tables and charts, third ed., Wiley, Chichester.

49. Amalanathan M, Hubert Joe I, Rastogi VK (2011) Density functional theory studies on molecular structure and vibrational spectra of NLO crystal I-phenylalanine phenylalanium nitrate for $\mathrm{THz}$ application. J Mol Struct 1006: 513-526.

50. Murray JS, Sen K (1996) Molecular Electrostatic Potentials, Concepts and Applications, Elsevier, Amsterdam 7-624.

51. Scrocco E, Tomasi J (1978) Electronic Molecular Structure, Reactivity and Intermolecular Forces: An Euristic Interpretation by Means of Electrostatic Molecular Potentials. Adv Quant Chem 11: 115-121. 